\title{
Interactive comment on "Dynamics of ionic species in Svalbard annual snow: the effects of rain event and melting" by Elena Barbaro et al.
}

\section{Anonymous Referee \#1}

Received and published: 16 July 2019

\section{General Comments:}

This study conducted a series of snowpit chemistry measurements through the spring season in Svalbard with the goal of determining the behavior of snowpack ionic species under the influence of melt and rainfall. The authors present a unique and very comprehensive dataset showing the seasonal-scale evolution of snowpack chemistry in relation to melt and meteorology.

The dataset presented is valuable to our understanding of melt and rain processes and snowpack chemistry and is worthy of being published in a journal such as The Cryosphere. I also commend the authors on the study design and the huge amount of work required to undertake this study. 
However, as a manuscript, this paper has several major problems and is not yet suitable for publication. First, the paper contains many errors throughout the manuscript that make the results and the quality of the interpretations very difficult to assess. Figures are referenced incorrectly (or not at all), there are many typos, problems with tense and pluralization and sections of informal or unpolished writing.

While I have confidence in the data themselves, the statistical interpretations of the data were poorly described and were seldom justified by the authors. It is not clear that any of the results or discussion added any insight other than what would be immediately apparent by simply viewing the data. The discussion seems to be an extension of the results, describing the changes in snowpack chemical properties without providing much insight into the mechanisms and processes at play. Aside from a very discrete section on elution sequence, there were insufficient references or context. The few conclusions that the study draws, such as the elution sequence and the effects of the rain events, are not necessarily well-supported by the data (see specific comments).

As it stands currently, this work would be most suitable for a data publication (on the Arctic Data Center, Pangaea or other repositories). Improving the manuscript as it stands would involve bringing in a wider variety of literature - particularly on chemical properties and behavior of ions. I would recommend a more thorough use of meteorological data that potentially includes back trajectory modeling or a comparison of the results with reanalysis products. Many of the problems can be fixed relatively easily with more thorough explanations and clearer writing. I hope that the authors proceed with publishing these results in some form as they represent a tremendous effort and an impressive dataset.

\section{Specific Comments:}

I have not made an exhaustive list of mistakes and typos, but some are listed here in addition to specific scientific comments.

Printer-friendly version

Line 26: Also Denali and Logan ice cores have very little/no melt. Consider rephrasing 
to "Nearly all ice core archives from the Arctic and middle latitudes, aside from very high elevation sites in Greenland and the North Pacific, are strongly influenced......"

Line 28: "in the higher ice cap" - do you mean at higher elevations on ice caps in general? Or do you mean higher latitudes? Or are you referring to a specific ice cap?

Line 50: Should be "Dansgaard et al." - at least according you your references on line 570.

Line 53: "For example", not "For examples"

Lines 50-65: I think there should be some acknowledgement that while the interpretations listed for each chemical compound listed are commonly used, there is still considerable variation in what each of these proxies mean among sites and a host of factors influencing each of these chemicals.

Line 71: Change to either "over glaciers" or "over the glacier".

Line 74: Higher altitudes or latitudes or both?

Line 78: change to "dependent"

Line 99-111: Very good summary of this project

Lines 106-107: More details are required here. Did you drill a new $100 \mathrm{~cm}$ ice core each day and place the ice in a continuous melter system in order to measure physical properties? Why didn't you also sample chemistry if you are going through all this effort? If I am misunderstanding, then more clarification would be helpful.

Lines 118-122: Are these statistics for Ny-Alesund or for your study site? If for NyAlesund, how much difference would you except in temperatures at your study site that those you report here, if any?

Lines 143-149: This section is presented well.

Lines 195: It is likely that the orography of the ice cap, the 270 meters of elevation dif- 
ference and the albedo differences will also lead to differences in temperature between the station and the field site.

Lines 248-249: Why did you choose these sampling intervals?

Lines 274: You reference Fig. 2, but these data are shown in Fig. 1. Fig. 1: It would be helpful and more quantitative to show the air temperature as a line graph instead of, or in addition to the colorscale displayed in Fig. 1B.

Lines 280-282: If you don't use the data from $50 \mathrm{~cm}$ depth after Apr. 18, then it should be removed from Figure 1. Currently it is by far the most striking feature in Fig. 1A and misleading if you think the data are unrealistic because the sensor was broken.

Lines 283-284: You say there was no liquid water was detected at the $75 \mathrm{~cm}$ depth, but in the next sentence you say that there was liquid water at $75 \mathrm{~cm}$ after May 26 . These statements should be reconciled.

Lines 288-302: Since this section essentially describes Fig. S1, I would either move this section to the supplement or move Fig. $\mathrm{S} 1$ into the main body of the paper.

Line 314: What do you mean by "considering both the literature"?

Line 321: There is no figure 4. Do you mean Fig. 3 ?

Line 322-327: These different concentration levels do not stand out to me for most of the plots in Figure 2 and Figure 3 (referenced as Fig.4). How were they chosen? It is also not clear yet, why it is necessary to group data from 10 depth levels into either 3 or 4 depth levels. This is especially true given that the authors just states on lines 318-320 that many of these ions have multiple sources, so it may not make sense to impose differential groupings on the data.

Printer-friendly version

Figs. 2-3: This is a nice way to represent the data. It is a very impressive data set.

Lines 349: To me, it looks like the decrease is only apparent at $50 \mathrm{~cm}$. Is there a statistically significant decrease anywhere else? 
Lines 349-350: There is no Table S2. Do you mean Table 2? Or Table 1 ?

Table 2: Just to clarify: are the values in table 2 calculated from the methods described in lines 252-261? In the figure 2 caption or in the results or discussion, it would be useful to be more explicit than you are when comparing changes in mean concentrations between phases 1, 2 and 3 of different chemicals.

Line 353: What has led you to conclude that the increase in suflate and iodine is biogenic? You haven't given any justification yet.

Line 359: At what contrast? Do you mean "in contrast", or are you talking about the difference between P2 and P3?

Line 360: Do they all decrease significantly? It is not completely clear in Figure 3. What are the significance values and how did you calculate them? Are they in a table?

Line 362: What statistical analysis? How were the p-values calculated? I assume this is using the procedures described in lines 252-261, but you need to remind us. Also, why were these methods chosen? How are they different than a more standard t-test or ANOVA? Have other studies used these methods?

Line 366: What are we supposed to see in these time series plots? I think they are very helpful and probably should be brought to the reader's attention earlier (for instance during the discussion of the shifts between P1, P2 and P3). Figure S4: There are two figures labeled Figure S4. One should be changed to Figure S5.

Line 371 : Is this $80-100 \mathrm{~cm}$ depth on your normalized depth scale or relative to the surface at the time?

Line 376: This statement does not appear to be true for all of the ionic species. Are you referring to only the ions in Figure 3 but not those in Figure 2? If so, why? And why do some species like chloride not show higher concentrations at depth?

Printer-friendly version

Line 383: Do you mean that there is ice free ocean south of Svalbard? Please correct 
this sentence to clarify and fix the grammatical errors.

Lines 379-385: If I understand this section correctly, you argue that that the rain events are from open water areas further to the south, which you infer will have higher ion concentrations. Do you have any data to support this assumption or are there any other studies you can reference that have led you to this conclusion. Since you know the dates of snow and rainfall, and you have been sampling ion concentrations in surface snow, I think you could test this hypothesis with the data in hand. There are a wide variety of tools that can constrain the moisture sources of storms at specific dates. I recommend you further investigate these assumptions using the data you have collected, perhaps combined with back-trajectory modeling to support this discussion.

Line 385-387: It sounds like you are saying that snow = lower concentrations and melt $=$ higher concentrations. This is not necessarily true. Snowfall events can have extremely varied ion concentrations, depending on the source and trajectory of the air mass. And melt can enrich some areas of the snow and dilute other areas. If I have misinterpreted this sentence, then please clarify.

Line 400: Change to "temperature".

Line 404: What statistical approach? Please give details about what you actually did, quantitatively.

Lines 410-420: I'm not sure this is a good way to define the elution sequences among a group of ions. You may have a species with a very low magnitude of elution that is still statistically significant or a high magnitude of elution that is not significant. Just because one ion has a more favorable $p$ value, doesn't necessary mean that that ion elutes first or most strongly. I appreciate the effort involved in sampling snowpits every day, but you do not have a huge number of samples, they are all within a single year and they are affected not just by melt, but many other things as well. Finally, since I don't even know what test you are doing to calculate these $p$ values, I don't know what they mean physically. 
Line 423: Why would bromide have a positive level shift? How does this fit with your arguments?

Line 425: How do you know this? It doesn't look like you have made any measurements below $100 \mathrm{~cm}$.

Line 432: Why do you think this? Is this just speculation? Or are there other studies that have shown this? This could be interesting, but you need to back up this claim with a more thorough and fully referenced description of the physical mechanisms you infer.

Line 444: Figure 2 only goes as deep as $100 \mathrm{~cm}$, so how do you know this? There is no Figure 4.

Line 449: Why do you assume a continuous input of biogenic compounds, but not of saline compounds? Why are the saline ions depleted by melt while the biogenic ions appear to be unaffected? What about the chemistry of these ions would be consistent with your data?

Line 456: This paragraph is very full of typos and grammatical errors and is very hard to interpret.

Line 499: What statistical approach?

Interactive comment on The Cryosphere Discuss., https://doi.org/10.5194/tc-2019-124, 2019. 